\title{
The Effects of Friction Coefficient on Formability Behaviour of Dual Phase Steel
}

\author{
Ísmail Tekaut $*$ *[0 \\ ${ }^{a}$ Gazi Universitesi, Ostim MYO Ankara, Ankara, 06500, Turkey
}

Received: November 26, 2018; Revised: September 11, 2019; Accepted: September 25, 2019

\begin{abstract}
The effects of friction coefficient on formability behavior of advanced high-strength steel sheets have been examined in this study. For this purpose, forming analysis has been conducted by stretching the three different steel sheets such as DP600, DP800 and DP1000. Forming processes have been done by using punch that has different friction coefficients $(0.05,0.15,0.3,0.6 \mu)$ in nakajima forming die. As a result of the analysis, it has been observed that thinning amount and forming force have increased by the increasing in the friction coefficient. When major and minor deformations on the sheet have been examined, it has been determined that the increasing friction coefficient makes plastic deformation amount increase.
\end{abstract}

\begin{abstract}
Keywords: dual phase steel, surface roughness, friction coefficient, formability, DP600, DP800, DP1000
\end{abstract}

\section{Introduction}

When the sheet metal materials used in the automotive sector are examined, it is seen that the materials which provide light and high strength are preferred. Reducing vehicle weight that decreases carbon emissions and fuel consumption results in environmental and economic gains. For this purpose, the use of advanced high strength steels developed in the automotive industry has increased ${ }^{1,2}$. Dual phase steels have an important place within the types of high-strength steels. There are two different phases, with various fraction volume in the microstructure of dual phase steels, as hard martensite which provides strength and soft ferrite which provides ductility and formability ${ }^{3,4}$.

Nowadays, sheet metal forming processes are used in the process of production of many parts in the automotive sector. In the production stages of the sheet metal parts, the sheet metal material is formed by plastic deformation in accordance with the desired geometry. The formability of the material during the production varies according to deformation conditions and material properties. Under these conditions, it is known that the thinning amount, forming limit diagrams and forming force are effected in the stretch forming process while determining the formability of sheet metal materials ${ }^{5}$. In the literature, Figueiredo et al. have determined that the surface roughness of the die plays an important role in the friction that is occurred in sheet metal forming processes ${ }^{6}$. Karupannasamy et al. have examined the effect of lubrication in the deep drawing process by using finite element method in their study. They have concluded that the friction coefficient is not constant in the forming process ${ }^{7}$. Casari et al. have examined the effect of lubrication on the forming limit diagrams. It has been observed that the friction coefficient is decreased by the effect of lubrication and reduces the major deformations to the lower level ${ }^{8}$. Ozturk and Lee have examined the effect of lubrication between the sheet and die in their study and they have determined that the lubrication reduces the forming forces ${ }^{9}$. Ma et al. have examined the effect of the friction on deep drawing process under the heat effect. They have reported that the friction coefficient significantly affects the amount of thinning ${ }^{10}$. Sing et al. have examined the effects of friction coefficient on forming of Usibor 1500 steel and they have determined the low friction coefficient improves the formability ${ }^{11}$. Huang et al. have reported that the forming force of zinc stearate lubricant provides positive results on thickness distribution and increases the deep drawing ratio ${ }^{12}$. It is concluded that factors such as lubricant/friction coefficient are effective on the formability of sheet materials in those studies. However, it has been observed that the effects of friction coefficient on forming of dual phase steel sheets are not examined even if it is widely used in the automotive industry.

In this study, the effects of the friction coefficient have been compared on the forming of three different advanced high-strength dual phase steel sheet such as DP600, DP800 and DP1000. 


\section{Material and Formability Simulation}

The advanced high-strength steel sheets such as DP600, DP800 and DP1000 as $1 \mathrm{~mm}$ thickness have been used in the forming analysis. In figure 1, microstructural images of dual phase steels are given. The microstructure images at $1000 \mathrm{X}$ magnification have been obtained using optical microscope. In the dual phase steel microstructure images, the light fields indicate ferrite phase, while dark fields indicate martensite phase. These steels are dual phase steels with different martensite volume fractions. The martensite phase volume fractions have been determined by image analysis method with using LAS v4.6 software. According the results, it has been seen that martensite volume fraction for DP600, DP800 and DP1000 are about \%27, \%37 and $\% 46$, respectively. The chemical composition of steel sheets is given in Table 1.

The forming process has been conducted in computer environment by stretching and modelling the nakajima forming die. Schematic view of nakajima forming die has been shown in Figure 2. In the analysis, forming behavior has been considered under the different friction coefficent values $(0.05,0.15,0.3,0.6 \mu)$. Punch movement distance is $40 \mathrm{~mm}$.

Mechanical properties of DP600, DP800 and DP1000 steel sheets were obtained from the literature and entered into the analysis software in order to perform forming analysis. The Mechanical properties are given in Table 2.

\section{Result and Discussions}

As a result of tensile forming analyses by using stretching, the amount of thinning, forming force and plastic deformation amounts of DP600, DP800 and DP1000 steel sheet materials were determined.

\subsection{Thinning}

The forming process begins when the punch moves into the nakajima forming die. The high holder force is applied to provide rigidness on the sheet between the blank holder and die. For this reason, the sheet cannot flow into the die sufficiently and begins to thin. The effects of friction coefficient on the amount of thinning of the dual phase steel sheets are given in Figure $3 \mathrm{a}$. With the increase of friction coefficient between $0.05-0.15 \mu$, there was a decrease in the amount of thinning in all three steel sheets. The decrease in the amount of both DP600 and DP800 steel sheets still goes on between $0.15-0.6 \mu$. However, it has been observed that the thinning increase rate of DP800 steel sheet is slower than DP600 steel sheet. Moreover, it is clear that friction coefficient in DP1000 steel sheet cannot be affected significantly by that increase. When the thinning amounts of steel sheets are compared, it occurs in DP600, DP800 and DP1000 respectively. In this case, it is concluded that the amount of thinning on advanced high-strength steel sheets get higher by increasing strength value. Furthermore, it has been found that the friction coefficient sensitivity has decreased on higher strength sheet during deformation. The amount of thinning from cup center to outside is shown in Figure $3 \mathrm{~b}-\mathrm{d}$. When the amount of thinning on the formed part is evaluated, it is understood that the maximum amount of thinning occurs on the side surface of the part. There was no significant change in the flange parts of the sheet. At high friction coefficient values, it has been found that the amount of thinning in the cup center is less due to the more difficult flow of the sheet towards the cup center point and the amount of thinning is higher when friction coefficient value is lower. It is thought that this situation can be caused by the easier flow of the sheet at low friction coefficient values.
DP600

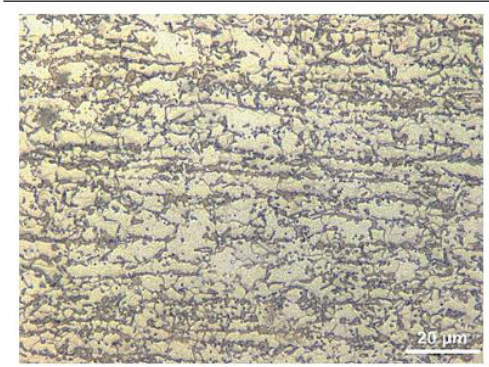

DP800

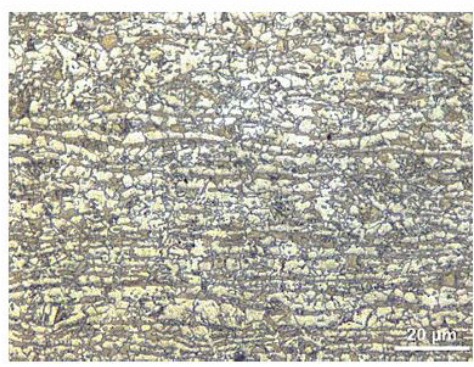

DP1000

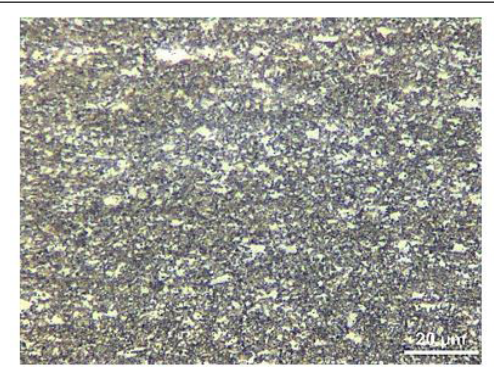

Figure 1. Microstructure images of DP600, DP800 and DP1000

Table 1. Chemical composition of DP600, DP800 and DP1000 steel (wt \%) ${ }^{3}$

\begin{tabular}{lccccccccc}
\hline Steel Grade & $\mathbf{C}$ & $\mathbf{M n}$ & $\mathbf{N i}$ & $\mathbf{C r}$ & $\mathbf{S i}$ & $\mathbf{P}$ & $\mathbf{S}$ & $\mathbf{C u}$ & $\mathbf{A l}$ \\
\hline DP600 & 0.07 & 1.58 & - & 0.48 & 0.10 & $<0.02$ & $<0.01$ & - & 0.03 \\
DP800 & 0.11 & 1.41 & 0.03 & 0.02 & 0.23 & $<0.02$ & $<0.01$ & $<0.01$ & 0.03 \\
DP1000 & 0.14 & 1.40 & 0.03 & $<0.02$ & 0.53 & $<0.01$ & $<0.01$ & 0.02 & 0.03 \\
\hline
\end{tabular}



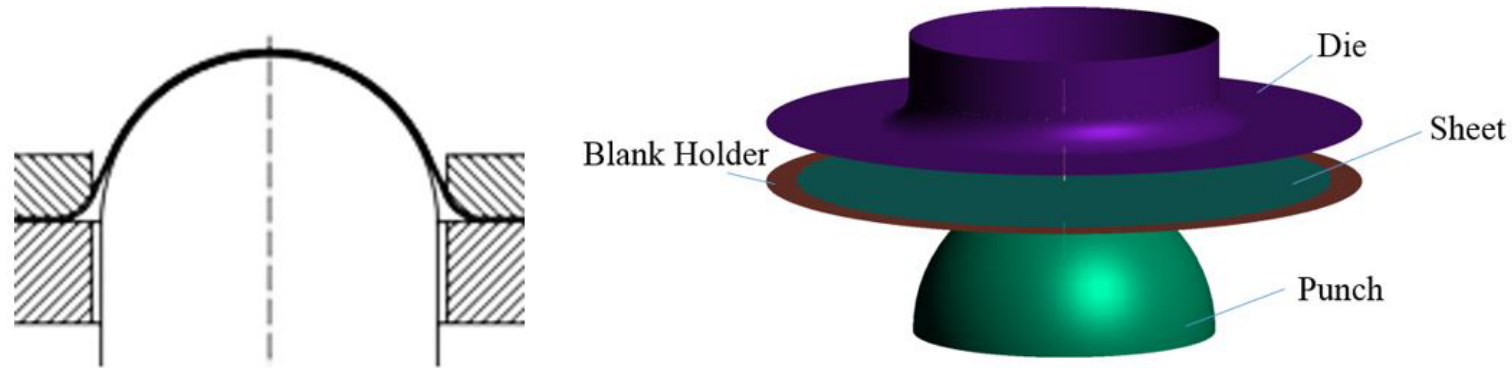

Figure 2. Schematic view of nakajima Forming Die

Table 2. Mechanical properties of DP600, DP800 and DP1000 steels ${ }^{13}$

\begin{tabular}{lcccccc}
\hline Steel & $\begin{array}{c}\text { Yield strength } \\
\mathbf{( M P a )}\end{array}$ & $\begin{array}{c}\text { Ultimate tensile } \\
\text { strength } \mathbf{( M P a )}\end{array}$ & $\mathbf{r}_{\mathbf{0}}$ & $\mathbf{r}_{\mathbf{4 5}}$ & $\mathbf{r}_{\mathbf{9 0}}$ & $\begin{array}{c}\text { Hardening } \\
\text { coefficient (n) }\end{array}$ \\
\hline DP600 & 412 & 676 & 1.16 & 0.67 & 1.02 & 0.206 \\
DP800 & 531 & 802 & 0.92 & 0.86 & 0.97 & 0.14 \\
DP1000 & 766 & 1075 & 0.88 & 0.85 & 0.95 & 0.075 \\
\hline
\end{tabular}
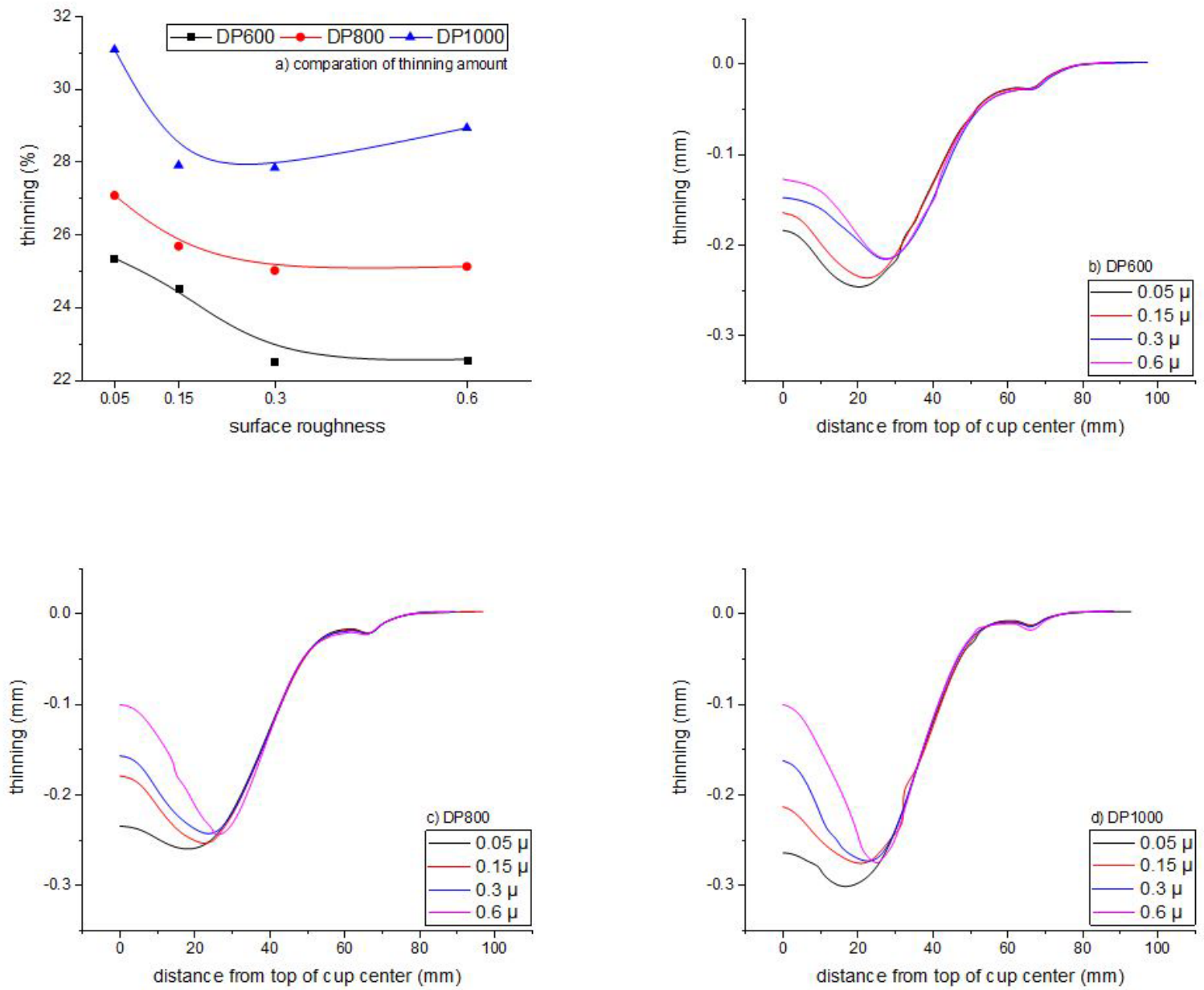

Figure 3. Thinning - friction coefficient relations 
In order to evaluate the formability of DP600, DP800 and DP1000 steel sheets, the obtained formability results depending on the amount of thinning as a result of forming analysis are given in Figure 4. When Figure 4 is considered, the increase of friction coefficient is respectively DP600, DP800 and DP1000; and it is observed that light-green areas with safe forming area decrease and orange-colored thinning zones increase. In this case, it is seen that the formability of the sheets is higher in low friction coefficient values.

\subsection{Forming force}

During the forming process, the response of the sheet to the punch movement is the forming force. Figure 5 shows the relationship between forming force and the friction coefficient. It is seen that the forming force increases with the increase of friction coefficient. However, the increase rate decreases between $0.3-0.6 \mu$. This situation is thought to be due to the fact that the sheet is less strength to deformation due to the increased friction coefficient values and plastic deformation in the sheet. When the forces occurred in the forming of steel sheets are compared, it is determined that DP1000 steel sheet has the highest forming force. Respectively, DP800 and DP600 steel sheets need lower forming force. The type of material is important for creating the forming force. The tensile strength of steel sheets increases by increasing the amount of martensite content ${ }^{3}$. Accordingly, the forming forces also increase. The forming force that is occurred by punch movement is given in Figure $5 \mathrm{~b}$ - $\mathrm{d}$. There is no significant difference in the forming force that is occurred depending on friction coefficient in the first stages of the punch movement. However, it is observed that there are differences depending on the effect of punch friction coefficient in the last stages of punch movement.

\subsection{Plastic deformations}

The deformation states formed in Figure 6 are examined by comparing the forming limit diagram with plastic deformation zones on the sheet material. In Figure $5 \mathrm{a}$, it is seen that all the friction coefficient values given for the DP600 steel are formed under the forming limit diagram and it is in the safe zone. In Figure $6 \mathrm{~b}$, it is clear that the material has been formed safely in $0.05 \mu, 0.15 \mu$ and 0.3 $\mu$ friction coefficient coefficients for DP800; however, the deformation causes cracking or tearing by exceeding the safe place in $0.6 \mu$ friction coefficient. In Figure $5 \mathrm{c}$, when

\subsection{5}

0.15

0.3

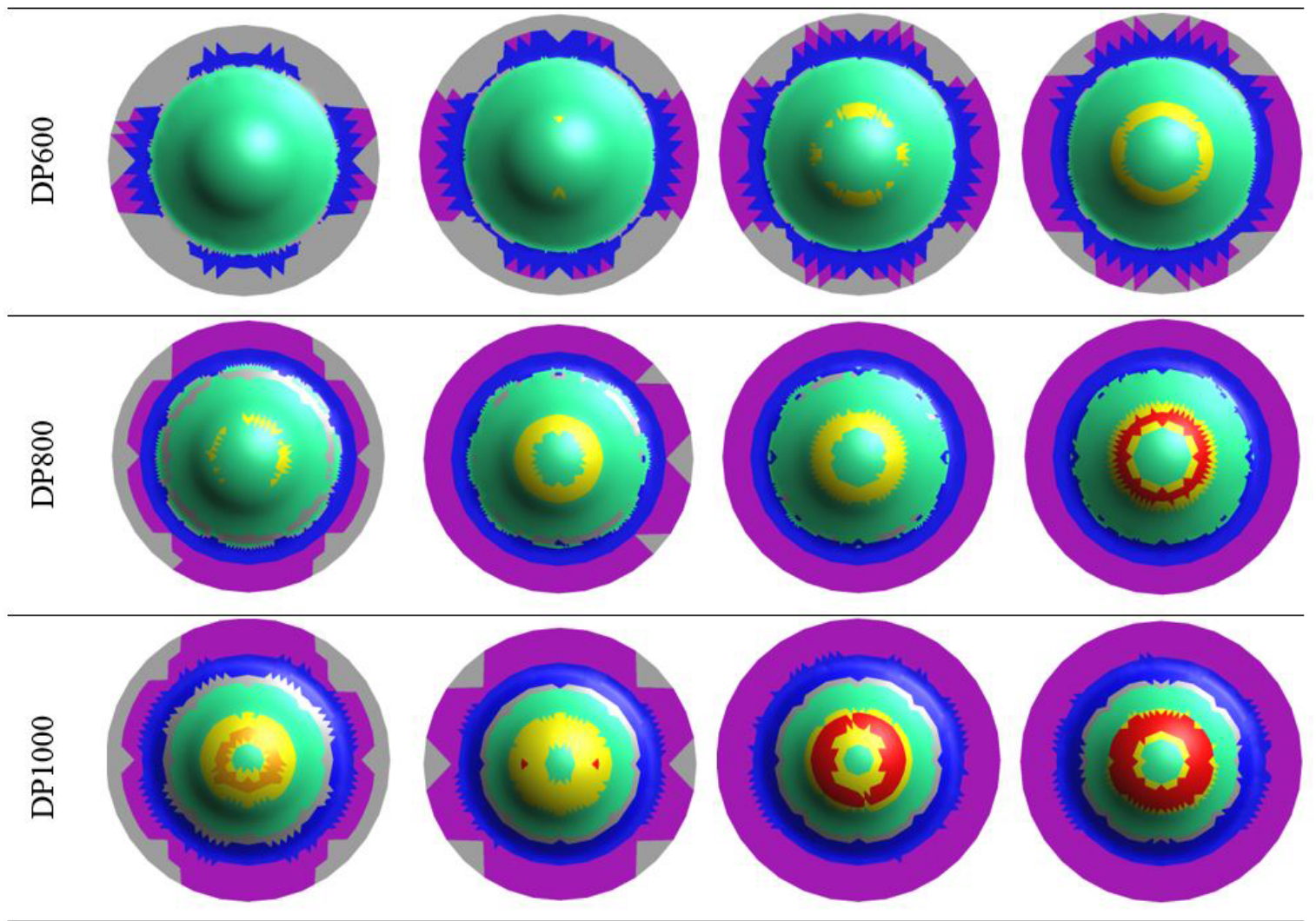

0.6

Figure 4. Comparison of formability behavior 

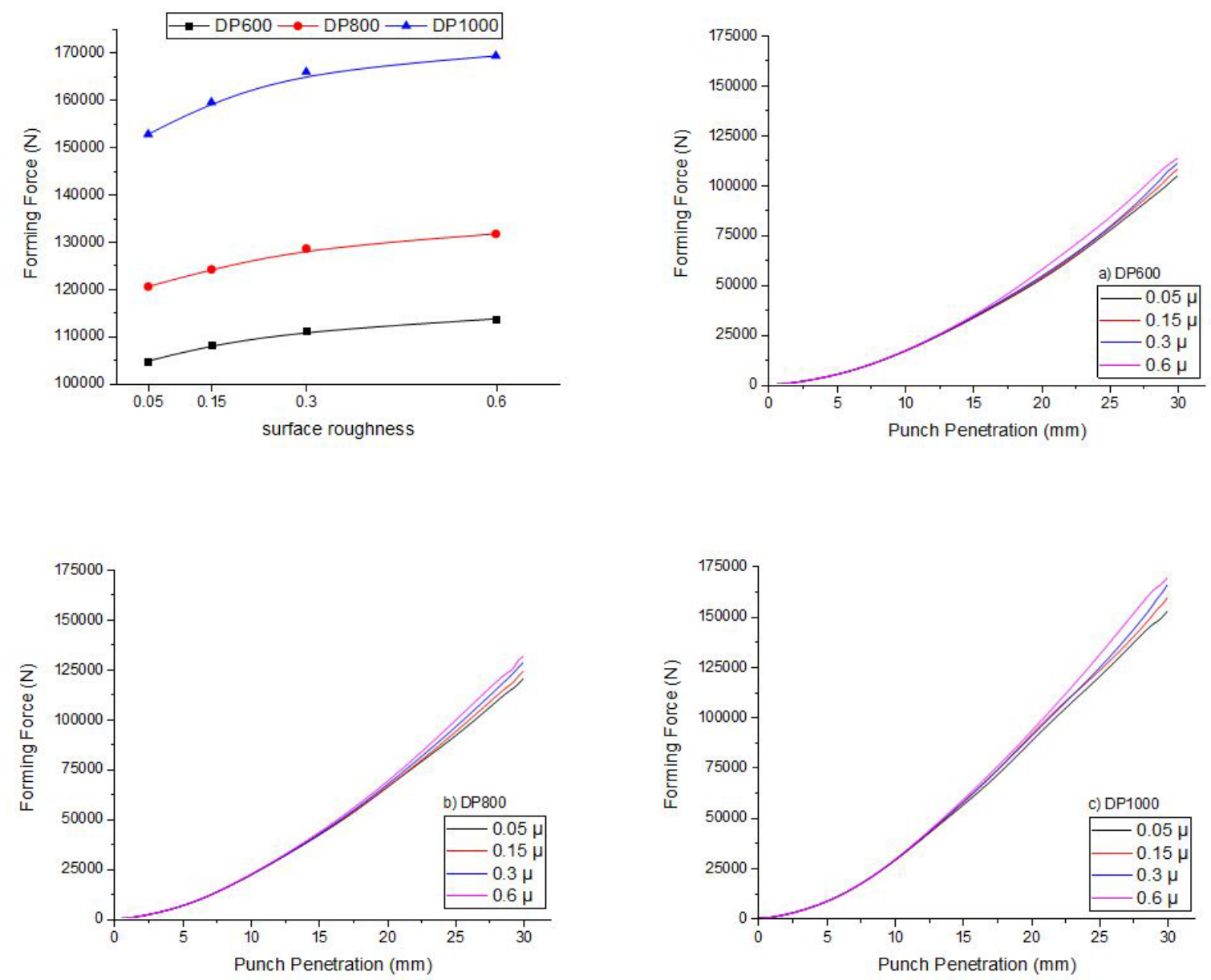

Figure 5. Forming force - friction coefficient relation
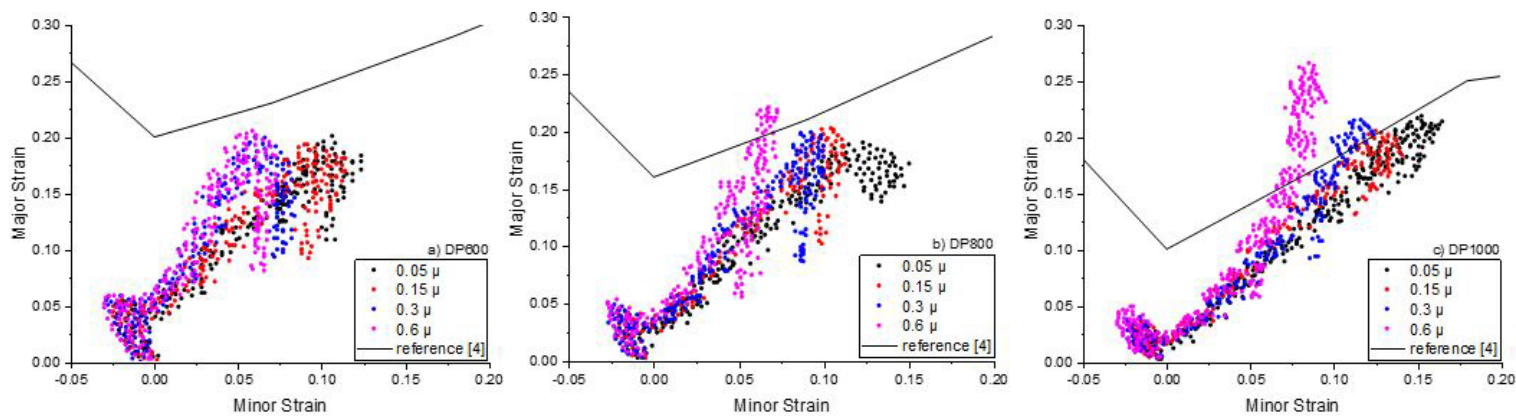

Figure 6. Strain distribution - friction coefficient relations

plastic deformation conditions in DP1000 sheet steel have been evaluated, it is seen that the forming process $0.05 \mu$ friction coefficient is successful. Considering the effect of friction coefficient on the forming of dual phase steels, the response from friction coefficient is respectively DP600, DP800 and DP1000 due to the increasing strength and decreasing ductility amount depending on the increase in martensite volume fraction.

\section{Conclusion}

The obtained results as follows:

- The evaluation amounts and forming force have been conducted as DP1000 > DP800 > DP600. In this case, it has been observed that the thinning amount and forming force increase when martensite volume fraction and $\mathrm{C}$ element ratio increase. The increase in friction coefficient has increased the amount of thinning. 
- When the formability behaviors of dual phase steel sheets are examined, DP600 steel can be formed safely but DP800 steel has the possibility of tearing in $0.6 \mu$ friction coefficient. There is the possibility of tearing in $0.15,0.3$ and $0.6 \mu$ friction coefficient values for DP1000. It has been determined that the increase of martensite volume fraction in the microstructure of dual phase steels has increased the friction coefficient sensitivity.

- Minor strains have decreased and major strains have increased on the sheet depending on the increase in the friction coefficient.

\section{References}

1. Khedkar P, Motagi R, Mahajan P, Makwana G. A Review on Advance High Strength Steels. International Journal of Current Engineering and Technology. 2016;(spe 6):240-243.

2. Lesch C, Kwiaton N, Klose FB. Advanced High Strength Steels (AHSS) for Automotive Applications - Tailored Properties by Smart Microstructural Adjustments. Steel Research International. 2017;88(10):1-21. Available from: https://doi.org/10.1002/ srin. 201700210

3. Çavusoglu O, Toros S, Gürün H. Microstructure based modelling of stress-strain relationship on dual phase steels. Ironmaking and Steelmaking: Processes, Products and Applications. 2019;46(4):313-319. Available from: https://doi.org/10.1080 /03019233.2017.1371959

4. Rana R, Singh SB, editors. Automotive Steels - Design, Mettalurgy, Processing and Applications. Oxford, UK: Elsevier; 2017. p. 83.

5. Çavusoglu O, Gürün H. Statistical evaluation of the influence of temperature and surface roughness on aluminium sheet metal forming. Transactions of Famena. 2017;41(3):57-64. Available from: https://doi.org/10.21278/TOF.41305

6. Figueiredo L, Ramalho A, Oliveira MC, Menezes LF. Experimental study of friction in sheet metal forming. Wear. 2011;271(910):1651-1657. Available from: https://doi.org/10.1016/j. wear.2011.02.020

7. Karupannasamy DK, Hol J, Rooij MB, Meinders T, Schipper DJ. Modelling mixed lubrication for deep drawing processes. Wear. 2012;294-295:296-304. Available from: https://doi. org/10.1016/j.wear.2012.06.006

8. Casari F, Tassan M, Messina A, Molinari A. Effect of Punch Diameter, Grid Dimension, and Lubrication on Forming Limit Diagram. Journal of Testing and Evaluation. 2006;34(1):12669. Available from: https://doi.org/10.1520/JTE12669

9. Ozturk F, Lee D. Experimental and numerical analysis of out-of-plane formability test. Journal of Materials Processing Technology. 2005;170(1-2):247-253. Available from: https:// doi.org/10.1016/j.jmatprotec.2005.05.010

10. Wang H, Wan M, Yan Y. Effect of flow stress-strain relation on forming limit of 57540 aluminum alloy. Transactions of Nonferrous Metals Society of China. 2012;22(10):2370-2378. Available from: https://doi.org/10.1016/S1003-6326(11)61473-8

11. Singh CP, Agnihotri G. Formability Analysis at Different Friction Conditions in Axis-Symmetric Deep Drawing Process. Materials Today: Proceedings. 2017;4(2 Pt A):2411-2418. Available from: https://doi.org/10.1016/j.matpr.2017.02.091

12. Huang YM, Cheng JW. Influence of lubricant on limitation of formability of cylindrical cup-drawing. Journal of Materials Processing Technology. 1997;63(1-3):77-82.

13. Wu-Rong W, Chang-Wei H, Zhong-Hua Z, Xi-Cheng W. The limit drawing ratio and formability prediction of advanced high strength dual-phase steels. Materials and Design. 2011;32(6):3320-3327. Available from: https://doi.org/10.1016/j. matdes.2011.02.021 